\section{Ambigüidade genital: a percepção da doença e os anseios dos pais}

\section{Ambiguous genitalia: perception of the disease and parents anxiety}

Carlos Antonio Bruno da Silva 1

Heleni B. de Brito 2

Erlane Marques Ribeiro 3

José Brandão-Neto 4

\section{Abstract}

Objectives: to identify how parents perceive and face genital ambiguity in their children during different development phases.

Methods: qualitative study based on the reports of 15 parents of different families on their children's development expectations. Performed at the clinic of endocrinologic and genetic diseases of the Hospital Geral César Cals of Ceará in 2004.

Results: subjects reported: fear and anxiety, and the feelings involved in the way they handled the condition were: denial; evasion; regression/projection and rationalization. The tension and anguish noted in the neonatal period are expressed by the fear of death, incurable disease and medication. During childhood, of the surgical procedure (ambiguous genitalia) and sexuality (homosexuality). During puberty and adulthood there's the fear of marginalization, prejudice, homosexuality and infertility. There is anguish related to pointing at the guilty party, sexual definition (ambiguity) and the need for secrecy.

Conclusions: ambiguous genitalia is a highly complex condition affecting the family psychological balance. In situations of genital ambiguity determining and demystifying fears and expectations should be part of the therapeutic plan.

Key words Genitalia, Hermaphroditism, Behavior, Parents, Child

\section{Resumo}

Objetivos: identificar a percepção e os mecanismos de enfrentamento utilizados por pais frente à ambigüidade genital de seus filhos em suas diversas etapas evolutivas.

Métodos: estudo qualitativo, baseado nos relatos de 15 pais, todos de diferentes famílias, sobre seus anseios no desenvolvimento da criança. Realizado no ambulatório de patologias endócrino-genéticas do Hospital Geral César Cals, no Ceará, em 2004.

Resultados: as categorias que emergiram através do discurso dos sujeitos foram: o medo e a ansiedade, e os mecanismos de enfrentamento foram: a negação; a fuga; a regressão/projeção e a racionalização. Observou-se que as tensões e angústias no período neonatal são expressas através do medo da morte, da doença incurável e dos medicamentos. No período infantil, do procedimento cirúrgico (genitália ambígua) e da sexualidade (homossexualismo). Na projeção da fase puberal e adulta há o temor da marginalização, do preconceito, da homossexualidade e da infertilidade. As angústias relatadas foram de quem seria a culpa, a definição sexual (ambigüidade) e a necessidade do segredo.

Conclusões: a genitália ambígua consiste em uma patologia de alta complexidade, que desestabiliza a harmonia psicológica familiar. Nas situações de ambigüidade genital, a detecção e desmistificação dos medos e anseios dos pais devem fazer parte do plano terapêutico.

Palavras-chave Genitália, Hermafroditismo, Comportamento, Pais, Criança 


\section{Introdução}

A situação de intersexualidade genital, que é definida como sendo a presença de características dos dois sexos em uma mesma genitália, foi reconhecida desde os primórdios da história. Foi representada na mitologia grega pelo deus Hermafrodito, filho de Hermes e de Afrodite, que por sua enorme beleza, inspirou forte paixão à ninfa Salmácis. Ela, tomada de grande amor, pediu aos deuses que os dois nunca fossem separados. Os deuses acederam e juntaram os dois amantes em um só corpo, criando um andrógino, isso é, um ser dotado de dois sexos. ${ }^{1}$

As condutas médicas nos casos de genitália ambíguas têm variado com as décadas. Inicialmente o intersexo era considerado uma emergência. A definição do sexo seguido de procedimento cirúrgico buscava a minimização das inadequações do sexo social. Atualmente já se cogita aguardar a criança atingir o período puberal ou de definição sexual para que ela opte pelo seu sexo definitivo. Essa atitude tem sido advogada a partir da constatação de que a exposição androgênica durante o período fetal pode levar a tendência de gênero masculino em crianças do sexo cromossômico feminino, especialmente em casos de hiperplasia adrenal congênita, onde há uma síntese e liberação anômala de hormônios androgênicos pela glândula suprarenal.2,3 O quê deparamos na clinica diária são situações e conflitos que ainda não permitem a espera do momento ideal e opta-se por uma intervenção precoce.

Os termos sexo e gênero, apesar de ocasionalmente serem utilizados como sinônimos, denotam dois conceitos diferentes. Sexo é entendido como a representação das características físicas do indivíduo. ${ }^{4} \mathrm{~A}$ definição de gênero é mais complexa, sendo definida como o conjunto de sentimentos, assertivas, atitudes e comportamentos a partir dos quais se reconhece o indivíduo como sendo menino, menina, homem ou mulher. 5

Já a homossexualidade, segundo Freud, consiste em uma perversão quanto ao objeto que não é prédeterminado, mas contingente, e a escolha heterossexual é tão enigmática quanto a homossexual. ${ }^{6} \mathrm{~A}$ negação da homossexualidade e da intersexualidade sempre foi alvo de preconceitos sociais. No fim do século XVIII e início do século XIX, os hermafroditos eram considerados monstros, executados, queimados e suas cinzas jogadas ao vento. ${ }^{7}$

As propostas terapêuticas, nos casos de crianças portadoras de genitália ambígua, têm focado a definição sexual com o objetivo de minimizar os possíveis traumas na criança ou, por outro lado, a resolução do dilema médico. $\mathrm{O}$ aspecto psicossocial da doença, das relações familiares, da aceitação das crianças portadoras por ela mesma e pela família, tem sido, em alguns serviços, renegados a um segundo plano em detrimento a gravidade do quadro. As novas propostas terapêuticas, não levando em consideração uma identidade social, propondo procedimentos reparadores mais tardios e a definição do gênero da criança podem vir a trazer danos psicológicos bem mais graves que os descritos atualmente. 8

Dentre as diversas causas de ambigüidade genital, na hiperplasia congênita de supra-renal (HCSR), em especial, as crianças adquirem posturas e situações de gênero atípicas com tendências de alienação. Esse quadro de alienação tende a evoluir para isolamento, para dúvidas, para crises existenciais e para quadros de depressão que podem assumir graus de profundidades variáveis. 9 As conseqüências da inadequação na fase infantil, quando não eficazmente trabalhadas, evoluem para a fase adulta. É demonstrada uma maior freqüência de gênero cruzado, menor índice de casamentos ou de cohabitação, menor taxas de experiências heterossexuais. 10

Até o início dos anos noventa o manuseio psicossocial de crianças portadoras de genitália ambígua foi renegado pela estrema gravidade do quadro ao nascimento. ${ }^{11}$ Nesse período ficou estabelecido que crianças com cariótipo $46 \mathrm{XX}$ fossem prontamente definidas como sexo feminino, que realizariam cirurgia reparadora ou corretiva, com a freqüente extirpação do clitóris. A reposição glicocorticóide e produção ovariana de estrógenos adequavam-se ao quadro, permitindo a síntese hormonal normal e mantendo a fertilidade. Apesar da agressão sofrida pela criança e pelos pais, aparentemente o problema estaria solucionado e o preceito de urgência estaria resolvido. Caso contrário pode se instalar uma tragédia social duradoura por toda a vida, tanto para o paciente como para a família. ${ }^{12}$

Este trabalho teve como objetivo identificar e analisar os sentimentos percebidos e reconhecer os mecanismos de enfrentamento utilizados por pais de crianças portadoras de ambigüidade genital com diagnósticos etiológicos variados; suas percepções, seus sentimentos e suas ansiedades diante da doença e quais as repercussões que poderiam advir dessas formas de reação na estrutura familiar.

\section{Métodos}

O estudo foi realizado no Ambulatório de Patologias Endócrino-Genéticas do Hospital Geral Dr. César 
Cals em Fortaleza, Ceará, Brasil. Desta população foram entrevistados os pais e mães de crianças portadoras de genitália ambígua, independentemente da doença de base, do sexo cromossômico, da idade, da raça e do nível socioeconômico. A franca exaustão e repetição das respostas foram utilizadas como critério de suspensão do estudo.

O grupo foi formado por 15 pais, sendo 12 mães e três pais, todos de diferentes famílias. As crianças variaram de três meses a sete anos. Foram nove crianças de sexo cromossômico XX, sexo social feminino e três crianças com sexo cromossômico $\mathrm{XY}$, sendo duas com sexo cromossômico masculino e um feminino.

Os sujeitos da pesquisa foram abordados para a realização das entrevistas durante o atendimento ambulatorial. Os objetivos da pesquisa foram esclarecidos, não tendo havido nenhuma recusa na participação. O total de atendimentos no serviço com diagnóstico de ambigüidade genital é de cerca de 40 crianças nas diversas fases da vida. O grupo de 15 pais (12 mães e 3 pais) participantes constituiu uma amostra representativa dentro do universo de 32 crianças em seguimento atualmente.

$\mathrm{O}$ estudo de enfoque qualitativo foi realizado a partir de entrevista com questões abertas. Para sua execução teve como pontos norteadores: a) os sentimentos, anseios e percepções e modos de enfrentamento utilizados imediatamente após o nascimento e ao saberem da doença do(a) filho(a); b) quais as suas percepções atuais frente a patologia e seus agravos sobre a criança e familiares; e, por fim, c) quais os anseios, receios, expectativas e perspectivas destes pais em relação ao futuro dessas crianças. As entrevistas foram gravadas e transcritas para análise e avaliação das falas.

A análise e a interpretação dos dados foram realizadas a partir da categorização empírica das falas dos pais e responsáveis, buscando examinar as associações e as variações entre as respostas obtidas. Após leitura repetida das falas dos sujeitos, procedeu-se a análise do material coletado durante as entrevistas, em seguida o conteúdo presente nos discursos foi organizado por semelhança em núcleos de sentido e, por conseguinte, agrupados em categorias.

Os pais, que concordaram em participar do estudo, assinaram o Termo de Consentimento Livre e Esclarecido, o qual foi elaborado baseando-se na resolução 196/96 do Conselho Nacional de Saúde. O projeto foi submetido e aprovado sem restrições pelo Comitê de Ética em pesquisa da Universidade de Fortaleza.

\section{Resultados e Discussão}

Para a análise das falas e percepções optou-se por uma abordagem psicanalítica. Atualmente a sexualidade humana é vista de diversas formas pelas diferentes escolas de pensamento: pode ser apresentada como uma teoria de relacionamentos inter e intra-subjetivos com objetos significativos do mundo interno povoado de relacionamentos entre objetos internos. ${ }^{13}$ Optou-se, neste trabalho, por se conceber a sexualidade a partir do conceito de "gênero nuclear" e identidade do papel sexual, considerando o lugar da sexualidade como um universo somatopsíquico: a base libidinal de todas as sublimações e das pulsões de vida e de morte, apresentada como uma teoria de relacionamentos inter e intra-subjetivos com objetos significativos do mundo externo. 13

As duas categorias que se destacaram nas falas dos pais foram: o medo e a ansiedade e as principais formas de enfrentamento foram: a projeção, a negação/fuga e a racionalização.

\section{Medo}

No presente estudo a categoria mais freqüente, independente do sexo, idade dos pais, grau de expressividade e gravidade de doença foi o medo. Define-se o medo como um estado emocional inspirado pela presença, real ou pressentida, de um perigo concreto. Caracteriza-se por várias alterações no comportamento, desde fuga ao escondimento. Essa foi considerada uma categoria universal por ter sido referida por todos os pais e todos os familiares.

\section{"... Doutor, estou em pânico em saber}

destas coisas, como vou dar este mundo de remédios..." (mãe).

"Quer dizer que meu filho pode morrer a qualquer momento..." (mãe).

O foco do medo variou enormemente de acordo com a idade e a gravidade do quadro. Há o surgimento de um problema social de extrema gravidade. O trinômio: pais com sua ansiedade de definição sexual da criança, o médico sob extrema pressão familiar, o recém-nascido sem sexo definido, sem identidade.

"As necessidades dos pais nos dias imediatamente após o nascimento são complexas. Para alguns pais os primeiros dias são horríveis. É devastador para eles ouvirem dos médicos que estes estão encontrando dificuldade de definir o sexo da criança. Afinal eles são a razão genética daquela criança" (Warne e Zajac; 1998: 945). 3 
Ao nascimento, a evidência da malformação genital associa-se ao de alto risco de mortalidade, especialmente nas hiperplasias adrenais congênitas. A iminência da morte, a sobrecarga de exames e procedimentos invasivos na criança e a responsabilidade do controle medicamentoso desviam a atenção dos pais do foco da anormalidade. O medo se projeta para a gravidade do cenário como um todo, onde a ambigüidade passa a ser apenas mais um item.

No período infantil, quando se iniciam os preparativos para a intervenção médica reparadora, surge o medo relacionado ao sucesso do procedimento cirúrgico (genitália ambígua) e o da sexualidade (homossexualismo). Os pais ficam mais atentos quanto à sensualidade da criança. As brincadeiras, os brinquedos e os jogos que possam "significar" um comportamento homossexual ou sexual precoce são instintiva e imediatamente coibidos, conforme vemos nas falas dos pais:

"... Um dia ela beijou um priminho na boca

... No outro dia beijou a prima, aí eu a chamei e expliquei que não podia ..." (mãe)

Os pais, de forma mais intensa que as mães, durante as consultas, demonstram cobrar condutas e comportamentos quanto à sexualidade da criança em fases nas quais ainda não houve qualquer descoberta. Eles expõem seus preconceitos e pré-julgamentos com o objetivo de coibir futuras possíveis tendências homossexuais.

(pai)

"... Pra mim sapatão é coisa do demônio ..."

Estudos comportamentais sistemáticos em meninas com hiperplasia adrenal congênita têm demonstrado que essas meninas são masculinizadas e defeminizadas de várias formas; comparadas com suas irmãs, elas brincam mais freqüentemente com brinquedos masculinos e são mais agressivas quando provocadas, além de demonstrarem um menor interesse em outras crianças e em bebês. 5

\section{Ansiedade}

"... Doutor... Toda criança tem nome na incubadora e o meu tem RN de Maria ... Além do mais, todos têm estetoscópio azul ou rosa e o meu é cinza ..." (mãe ansiosa em definir o sexo).

Para Freud, a tarefa fundante da psique é encontrar estratégias de enfrentar a ansiedade, a qual é provocada por um aumento da tensão ou desprazer, podendo surgir em qualquer situação real ou imaginária que ameace a integridade física ou psíquica, sobretudo quando a situação é forte demais para ser ignorada, dominada ou descarregada. As situações prototípicas que causam ansiedade incluem a perda de um objeto desejado, além de rejeição ou fracasso em obter o alvo pretendido. O depoimento acima parece ser ilustrativo de ansiedade decorrente da perda do filho idealizado. ${ }^{14}$

As formas de enfrentamento desenvolvidas pelos pais apresentaram-se bastante variadas. Diversos fatores influenciaram as respostas. O mais importante é o tempo de convívio com a doença. À medida que o tempo passa, os pais se adaptam à situação dos filhos, a racionalização torna-se mais evidente e a necessidade de solucionar o impasse torna-se primordial. A escolaridade dos pais constitui outro critério importante na estruturação do enfrentamento psicológico, e associada ao poder aquisitivo foram determinantes primordiais na elaboração das novas situações vivenciadas pelos pais. Aqui se contemplam não só os anos de estudo, mas a capacidade de obtenção e de entendimento de informações. A religiosidade como forma de suporte psicológico e a ocorrência de casos semelhantes na família ou em outros filhos foram outros fatores que influenciaram na percepção dos pais. As principais formas de enfrentamento foram: a projeção, a negação/fuga e a racionalização.

\section{Projeção}

"... Mas de quem é a culpa?, na minha família não tem disso. Só pode ser culpa dela ..." (relato do pai referindo-se à mãe).

O mecanismo de defesa denominado de projeção, no qual o "ego" se protege da ansiedade, repelindo seus "maus objetos" e projetando-os em objetos externos, neutraliza esse sentimento, na medida em que conserva apenas, incorporados, os bons objetos.

O indivíduo exterioriza e atribui a outros suas idéias, motivos, defeitos, atitudes que ele censura e condena. Ao culpabilizar o outro, inconscientemente estaria tentando aliviar a suposta culpa que atribui a si próprio.

\section{Negação/fuga}

Alguns pais assumem uma posição de negação frente à criança. Na percepção das mães, os pais procuram eximir-se de qualquer culpa e na consciência de se tratar de uma doença genética, alguns optam por fugir da responsabilidade.

"... Meu marido me deixou logo depois que ela nasceu ..." (mãe) 
A negação consiste na tentativa de não aceitar na consciência algum fato que desestabiliza o "ego". Ocorre em adultos que tendem a fantasiar que certos acontecimentos não são reais ou que nunca aconteceram. Ela pode tomar várias formas, uma delas é a fuga, em que o indivíduo foge do contexto, negandose a enfrentar o problema. ${ }^{14}$

Nas situações de ambigüidade genital é freqüente o pai excluir-se. É notória a ausência dos pais nas consultas de seus filhos. Ele passa a negar a situação freqüentemente abandonando a estrutura familiar, passa a não comparecer às consultas médicas da criança, não assume a responsabilidade da medicação, nega-se a realizar exames. Quando questionado refere-se ao problema como sendo exclusivo da mãe.

$$
\begin{aligned}
& \text { "... O filho dela já amanhece o dia } \\
& \text { tomando remédio ..." (pai) }
\end{aligned}
$$

\section{$\underline{\text { Regressão }}$}

Ao receber o diagnóstico da doença da criança ocorre uma confusão nos referenciais de sentimento dos pais. Exterioriza-se o medo da morte, da doença incurável e dos medicamentos.

"Eu chorei muito ... Só pensava que não

ia ver ele falando e andando ... " (mãe)

"Meu marido não consegue compreender

por mais que se explique. Ele só chora

sozinho em um canto ..."

O mecanismo de regressão, que se trata de um retorno a um nível de desenvolvimento anterior ou a um comportamento infantil diante de um problema ansiogênico, consiste em um mecanismo de defesa arcaico e primitivo que, apesar de reduzir os níveis de tensão, não apresenta solução para o problema. 15

\section{Racionalização}

"... é melhor dizer que vai tomar remédio o resto da vida do que saber que não tem jeito nenhum."(mãe)

"... Cada um tem o dia de morrer determinado por Deus. Às vezes penso que foi Deus que tirou ela de mim ... Por mais que a mãe sofra, mas Ele sempre faz o que é certo ... Eu tinha medo de perder minha outra filha ... a primeira é do mesmo pai e morreu ..." (Uma mãe perdeu a primeira filha portadora)

A racionalização foi outra estratégia de defesa observada em alguns discursos. Trata-se de uma tentativa de manter o ajustamento livrando-se da ansiedade, apresentando motivos aparentemente lógicos e racionais. Na racionalização o indivíduo expressa uma justificativa aceitável para uma atitude, ação, ou sentimento gerador de angústia. Desse modo, a racionalização é uma maneira de acatar as pressões egóicas, disfarçando os verdadeiros motivos, tornando o inaceitável mais aceitável. A racionalização funciona como um impedimento ao desenvolvimento emocional, uma vez que impede o indivíduo de aceitar e de elaborar as reais fontes motivadoras de ansiedade.

Com o passar do tempo, especialmente nos casos de ambigüidade genital secundárias às hiperplasias adrenais congênitas, o sistema endocrinológico da criança torna-se mais eficaz. ${ }^{8}$ As intercorrências mórbidas tornam-se mais esparsas e o medo da morte surge em menor intensidade, pois os pais estão mais seguros e habituados a reconhecer sinais de insuficiência adrenal. Passa a haver o entendimento empírico da hereditariedade da doença. O sentimento de conformação e aceitação da doença é mais forte.

A classe social de origem dos pais, o grau de escolaridade, o nível cultural, os valores e preconceitos, a rede de relacionamentos e o local de moradia (zona urbana ou rural) são fatores determinantes no entendimento, na compreensão, aceitação e convivência no que se refere à opção sexual.10

"... Às vezes eu penso no sexo dela eu sei que tudo que Deus faz é bem feito mas o dela é tão diferente !!... (depois da cirurgia) não ficou do jeito certo de uma criança ... eu só penso se ela vai ter filhos.. Se vai poder fazer exame ginecológico como nós mulheres" (referindo-se à penetração da atividade sexual) ..." (mãe)

"... Só vem coisa ruim na minha cabeça: se o marido vai gostar dela. Tem muita gente com preconceito ... Eu não vou contar a ninguém, pois não quero que a chamem de Buba (personagem de novela) ou de machofêmea ..." (mãe)

$\mathrm{Na}$ fase puberal e adulta os pais projetam o temor do filho ser marginalizado ou vítima de preconceito. A sexualidade e a infertilidade causam preocupação, mesmo conscientes dos riscos da hereditariedade da doença.

\section{Conciderações finais}

Os pais costumam construir uma imagem idealizada para o filho que irá nascer, sendo culturalmente motivados a projetar o futuro de um filho-sonho, no entanto, alguns recém-nascidos são bem diferentes 
da imagem desejada construída por esses. A situação parece agravar-se quando descobrem que o filho aguardado apresenta uma disfunção ou uma alteração congênita. Nesses casos os pais podem experimentar diversos sentimentos, tais como: frustração, ansiedade, tensão, angústia, medo, susto, desânimo, choque, revolta, culpa, perda, luto, tristeza e rejeição. Tendo sido preparados para receber filhos perfeitos, é natural que apresentem dificuldades em lidar com este filho diferente, real, que não corresponde às expectativas paternas.

$\mathrm{O}$ nascimento de uma criança promove mudanças significativas no lar e no clima emocional da família. Essas transformações são ainda mais intensas quando se refere ao surgimento de um bebê com algum tipo de transtorno. A frustração frente ao nascimento desse filho será proporcional à expectativa dos pais, ou seja, quanto maior for a expectativa maior será a frustração. Dentre o rol de expectativas delineadas pelos pais, o sexo do filho parece ocupar posição de maior relevância. Ao se depararem com a chegada de um filho hermafrodita, embora as reações possam variar de casal para casal, freqüentemente esses pais ficam desnorteados e experimentam principalmente um sentimento de luto, ocasionado pela perda do filho sadio e idealizado.

Sabe-se que um alto grau de tensão, ansiedade ou angústia decorrente de vivências frustrantes ou traumáticas pode promover desordem na estrutura egóica do indivíduo. Para fazer frente às situações geradoras de conflito, frustração, tensão e ansiedade,

\section{Referências}

1. Zolla E. The androgyne. Londres: Thames and Hudson; 1981.

2. Migeon CJ, Winsniewski AB. Human sex differentiation and its abnormalities: best practice. Res Clin Obstet Gynaecol 2003; 17: 1-18.

3. Warne GL, Zajac JD. Disorders of sexual differentiation. Endocrinol Metab Clin North Am 1998; 27: 945-67.

4. Spinola-Castro AM. Intersexo: aspectos éticos e psicológicos. Arq Bras Endocrinol Metab 2005; 49: 46-59.

5. Money J. A first person history of pediatric psychoendocrinology. New York: Kluver Academic; 2002.

6. Freud S. Conferências introdutórias sobre psicanálise: 1917. In: Obras psicológicas completas de Sigmund Freud. Rio de Janeiro: Imago; 1996.

7. Foulcault M. Os anormais: curso no colégio de France. São Paulo: Martins Fontes; 2001.

8. Merke DP, Cutler-Jr GB. News ideas for medical treatment of congenital adrenal hyperplasia. Endocrinol Metab Clin North Am 2001; 30: 121-35. o psiquismo humano desenvolve estratégias inconscientes, na perspectiva de proteger o "ego" contra a desestruturação e o desprazer. Existem diversos mecanismos de defesa, sendo que alguns são mais eficientes que outros, porém todos demandam energia psíquica e objetivam manter o ajustamento.

Os dados encontrados indicam que os pais apresentam muitas dificuldades em lidar com a situação concernente à ambigüidade genital dos filhos recémnascidos, situação para eles inusitada e sobre a qual não dispõem de informações e compreensão suficientes, nem tampouco foram preparados para vivenciá-la, acarretando tensões e ansiedades que os desnorteam e os desestabilizam emocionalmente. $\mathrm{Na}$ perspectiva de livrarem-se das tensões e ansiedades, as quais devem ser debeladas, para que não atinjam níveis insuportáveis que poderão comprometer seriamente o ajustamento dos pais, esses inconscientemente articulam estratégias para fazer frente à situação geradora de ansiedade. Nesse sentido, foram identificados diversos mecanismos de enfrentamento utilizados pelos pais como forma de lidar com a nova situação, que consistiram em racionalização, negação, fuga, projeção, dentre outros.

$\mathrm{O}$ estudo favoreceu a reflexão de que a ambigüidade genital é uma patologia de alta complexidade e que agrava diretamente a estabilidade psicológica da família, que necessita de suporte psicológico mais intensivo e uma maior atenção de modo a desmistificar os receios e angústias dos pais.
9. Berenbaum SA, Bailey JM. Effects on gender identity of prenatal androgens and genital appearance: evidence from girls with congenital adrenal hyperplasia. Endocrine are of special interest to the practice of endocrinology. J Clin Endocrinol Metab 2003; 88: 1102-6.

10. Zucker KJ. Intersexuality and gender identity differentiation J Pediatr Adolesc Gynecol 2002; 15: 3-13.

11. Hall CM, Jones JA, Meyer-Bahlburg HF, Dolezal C, Coleman M, Foster P, Price DA, Clayton PE. Behavioral and physical masculinization are related to genotype in girls with congenital adrenal hyperplasia. J Clin Endocrinol Metab 2004; 89: 419-24.

12. Donahoe PK, Crawford JD, Hendren WH. Mixed gonadal dysgenesis, pathogenesis and management. J Pediatr Surg 1979; 14: 287-99.

13. McDougall J. Teoria sexual e psicanálise In: Ceccarelli PR, organizador. Diferenças sexuais. São Paulo: Escuta; 1999. p. 11-27. 
14. Freud S. Psicologia das massas e análise do eu: 1921. In Obras psicológicas completas de Sigmund Freud. Rio de Janeiro: Imago; 1996.

Recebido em 9 de novembro de 2004

Versão final apresentada em 18 de outubro de 2005

Aprovado em 14 de novembro de 2005
15. Mezan R. Freud: a trama dos conceitos. 4. ed. São Paulo: Perspectiva; 1998. 